\title{
Editorial: The Role of Carbon Capture and Storage Technologies in a Net-Zero Carbon Future
}

\author{
Mai Bui ${ }^{1,2 *}$, Matteo Gazzani ${ }^{3}$, Carlos Pozo ${ }^{4}$, Graeme Douglas Puxty ${ }^{5}$ and \\ Salman Masoudi Soltani ${ }^{6}$ \\ ${ }^{1}$ Centre for Environmental Policy, Imperial College London, London, United Kingdom, ${ }^{2}$ Centre for Process Systems Engineering, \\ Imperial College London, London, United Kingdom, ${ }^{3}$ Copernicus Institute of Sustainable Development, Utrecht University, \\ Utrecht, Netherlands, ${ }^{4}$ Department of Chemical Engineering, Universitat Politècnica de Catalunya, Barcelona, Spain, \\ ${ }^{5}$ CSIRO Energy, Newcastle, NSW, Australia, ${ }^{6}$ Department of Chemical Engineering, Brunel University London, Uxbridge, \\ United Kingdom
}

Keywords: CCS, net zero emissions, $\mathrm{CO}_{2}$ removal, BECCS, direct air capture, hydrogen, industrial decarbonisation

\section{Editorial on the Research Topic}

The Role of Carbon Capture and Storage Technologies in a Net-Zero Carbon Future

\section{OPEN ACCESS}

Edited and reviewed by: Uwe Schroder, Technische Universitat Braunschweig, Germany

${ }^{*}$ Correspondence: Mai Bui m.bui@imperial.ac.uk

Specialty section: This article was submitted to Carbon Capture, Utilization and Storage,

a section of the journal

Frontiers in Energy Research

Received: 30 June 2021 Accepted: 08 September 2021 Published: 17 September 2021

Citation: Bui M, Gazzani M, Pozo C, Puxty GD and Soltani SM (2021) Editorial: The Role of Carbon Capture and Storage Technologies in a Net-Zero

Carbon Future.

Front. Energy Res. 9:733968. doi: 10.3389/fenrg.2021.733968
Carbon capture and storage (CCS) technologies are recognized as having an important role in providing a cost-effective approach to limit global warming to $1.5^{\circ} \mathrm{C}$ (IPCC 2014; IPCC, 2018). The transition towards net-zero $\mathrm{CO}_{2}$ emissions will present technical, economic, commercial and policy challenges for the deployment of CCS and $\mathrm{CO}_{2}$ removal technologies. The opportunities for deployment will be diverse, and will significantly depend on the specific conditions found in the different regions of the world. Factors like national policies, availability of local resources, infrastructure and economy features, breakdown of GHG emissions across sectors, and societal background and wealth will all interplay to create conditions that are either favorable or disadvantageous to the deployment of CCS. This special issue is a collection of articles that explore the role of CCS and $\mathrm{CO}_{2}$ removal technologies in delivering reductions to $\mathrm{CO}_{2}$ emissions for a net-zero carbon future. The collection of publications includes two reviews and six original research articles, which are summarized below.

Johnsson et al. maps the potential costs associated with integrating CCS into all industrial manufacturing plants in Sweden, illustrating the marginal abatement cost curve (MACC). This helps quantify the level of decarbonisation required and identify the types of $\mathrm{CO}_{2}$ point sources, e.g., fossil fuel $\mathrm{CO}_{2}$, or biogenic $\mathrm{CO}_{2}$. The study evaluated the $\mathrm{CO}_{2}$ capture costs of 28 plants in Sweden, including a petrochemical site, refineries, iron and steel plants, cement plants and pulp and paper mills. These plants generate $>500 \mathrm{kt} \mathrm{CO}_{2}$ of the annual emissions, which is $>50 \%$ of Sweden's total $\mathrm{CO}_{2}$ emissions from all sectors. The marginal abatement cost curve showed capture costs ranging between 40 and $110 € / t \mathrm{CO}_{2}$, depending on the emission source, and includes the cost of transport and storage (adds 25 to $40 € / t \mathrm{CO}_{2}$ ). Based on this type of analysis, a national strategy towards net-zero across the industrial sector could be developed, identifying the low-cost $\mathrm{CO}_{2}$ capture options and opportunities for cost reduction.

Hydrogen and electrification are possible strategies for the decarbonisation of industrial clusters. Herraiz et al. proposes a system that uses steam methane reforming (SMR) for hydrogen production and power generation with CCS. An integrated system with SMR and power plant with CCS was found to produce $696,400 \mathrm{Nm}^{3} / \mathrm{h}$ of $\mathrm{H}_{2}$ with a net power output of 651 MWe at a net thermal efficiency of $38.9 \%$ LHV. The authors also present new insights for the design 
and operation of reformers integrated with gas turbines and $\mathrm{CO}_{2}$ capture, demonstrating methods to improve efficiency.

There are also opportunities to deploy new technologies in the power sector. Wevers et al. evaluates the potential of Power-to-Fuel-to-Power systems in delivering net-zero GHG emissions in energy systems, also considering the life cycle assessment (LCA) of environmental impacts. For comparison, another system generating electricity from natural gas combustion with $100 \%$ carbon capture and storage is also evaluated. Of the different Power-to-Fuel-toPower systems, the hydrogen storage system had the lowest environmental impact in all categories. This study highlights the importance of LCA studies in identifying any negative environmental impacts associated with the deployment of new technologies.

Addressing the issue of high costs for technologies that remove $\mathrm{CO}_{2}$ from air is a key challenge. The technoeconomic study by Kiani et al. identified key areas of possible performance improvement with conventional absorption-based direct air capture (DAC) using monoethanolamine (MEA). The energy consumption of MEA-based DAC was found to be a function of key process parameters, including air humidity, $\mathrm{CO}_{2}$ capture rate, $\mathrm{CO}_{2}$ loading of the lean and rich amine and reboiler temperature. The base case MEA scenario resulted in a reboiler duty of $10.7 \mathrm{GJ} / \mathrm{tCO}_{2}$ and an electrical energy requirement of $1.4 \mathrm{MWh} / \mathrm{tCO}_{2}$, corresponding to a capture cost of $\$ 1,691 / \mathrm{tCO}_{2}$. The overall cost range of the DAC process was between $\$ 273-1,227$ per ton of $\mathrm{CO}_{2}$, varying with different economic parameters. The study found that significant cost reductions could be achieved with the use of low-cost materials, innovative absorption contactor, which operates at lower liquid-to-gas ratios, and an absorbent with low volatility to avoid a water wash.

In the case of bioenergy with CCS (BECCS), the cost of transporting biomass can represent a significant proportion of the final biomass price, and there will be costs associated with $\mathrm{CO}_{2}$ transport. Stolaroff et al. assessed the transport costs associated with BECCS projects using data for the United States. The cost-optimal combination of transport for each scenario was a function of the transport capacity and distance. Biomass transport by rail is the most competitive option for systems capturing and storing most of the biogenic $\mathrm{CO}_{2}$, e.g., gasification to hydrogen or combustion for electricity generation. For large projects storing $>1 \mathrm{Mt} / \mathrm{yr} \mathrm{CO}_{2}$ or transporting $\mathrm{CO}_{2}>1,000 \mathrm{~km}$, the lowest cost option for $\mathrm{CO}_{2}$ transport is pipeline. In contrast, $\mathrm{CO}_{2}$ transport by rail is more cost competitive for smaller BECCS projects. In cases where developers have flexibility to choose the BECCS project type and transport modes, the transport costs were between $\$ 20-40$ / $\mathrm{tCO}_{2}$ stored for projects with distances of hundreds of kilometers from the biomass source to the storage site.

Scenario-based assessments are particularly useful in identifying deployment hurdles and opportunities at a systems scale. The systematic review of 66 German energy and decarbonisation scenarios by Hahn et al. identifies "blind spots" in regards to scenario assumptions around BECCS technology options and applications. The review reveals that future scenario analyses need to incorporate other considerations, including a framework for land use change and emissions accounting (only considered in $\sim 10 \%$ of scenarios), as well as the impact of public acceptance on technology deployment.

Another key consideration highlighted by Fuss and Johnsson is that scenarios need to consider the technology deployment rate as well as ensure that the ramp-up in deployment is achievable. The conditions for BECCS in Sweden are particularly favorable due to the existing large point sources of biogenic $\mathrm{CO}_{2}$ emissions in the country. Despite the favorable conditions, the current deployment rate of BECCS is limited. To achieve Sweden's net-zero target by 2045, two ramp-up scenarios for BECCS were proposed. The study reveals that immediate introduction of political and economic incentives would likely be required to significantly accelerate deployment to the levels required for the target.

A review and analysis of the status and possibilities of CCS deployment in the Netherlands by Akerboom et al. indicates there are no significant technical challenges. Historically, CCS deployment has mainly been hindered in the Netherlands by the lack of a compelling socio-technical narrative. Owing to the shift in focus from power to industry, CCS is now deemed vital in the transition to netzero, offering the means to rapidly reduce $\mathrm{CO}_{2}$ emissions significantly. The narrative around CCS is more favourable. The prospects of CCS have also appeared to improve since the introduction of new financial mechanisms, as well as increased government support and social engagement. Fitfor-purpose legal frameworks and policy instruments will likely have an important role.

\section{AUTHOR CONTRIBUTIONS}

MB was the primary author of the Editorial. MG, CP, GP, and SS provided feedback and contributions to the paper.

\section{FUNDING}

The authors would like to acknowledge funding from the Research Councils UK under grants EP/N024567/1 (CCS from Industrial clusters and their Supply chains), NE/ P019900/1 (Comparative assessment and region-specific optimisation of GGR) and EP/T033940/1 (Multiphysics and multiscale modelling for safe and feasible $\mathrm{CO}_{2}$ capture and storage).

\section{ACKNOWLEDGMENTS}

The authors would like to thank and acknowledge Angel Galan Martín from the Universidad de Jaen in Spain for contributing to the development of this Research Topic. CP is a Serra Hunter Fellow. 


\section{REFERENCES}

IPCC (2014). Climate Change 2014: Mitigation of Climate Change. Working Group III Contribution to the Fifth Assessment Report. Cambridge, United Kingdom and New York, NY, USA: Intergovernmental Panel on Climate Change (IPCC).

IPCC (2018). Global Warming of $1.5^{\circ} \mathrm{C}$. Switzerland: Intergovernmental Panel on Climate Change (IPCC).

Conflict of Interest: The authors declare that the research was conducted in the absence of any commercial or financial relationships that could be construed as a potential conflict of interest.
Publisher's Note: All claims expressed in this article are solely those of the authors and do not necessarily represent those of their affiliated organizations, or those of the publisher, the editors and the reviewers. Any product that may be evaluated in this article, or claim that may be made by its manufacturer, is not guaranteed or endorsed by the publisher.

Copyright (c) 2021 Bui, Gazzani, Pozo, Puxty and Soltani. This is an open-access article distributed under the terms of the Creative Commons Attribution License (CC $B Y)$. The use, distribution or reproduction in other forums is permitted, provided the original author(s) and the copyright owner(s) are credited and that the original publication in this journal is cited, in accordance with accepted academic practice. No use, distribution or reproduction is permitted which does not comply with these terms. 